\title{
Student perceptions of a proposed generic e-learning template aligned with the Engineering Council of South Africa accreditations template
}

\author{
Luwes, Nicolaas $^{\mathrm{a}}$ and Van Heerden, Leanri ${ }^{\mathrm{b}}$ \\ ${ }^{a}$ Department of Electrical and Computer Engineering, Central University of Technology, Free State \\ (CUT), South Africa, ${ }^{\mathrm{b}}$ Centre for Innovation in Learning and Teaching, Central University of \\ Technology, Free State (CUT), South Africa.
}

\begin{abstract}
The Engineering Council of South Africa (ECSA) audits engineering programmes every four years to grant accreditation to higher education institutions. During this audit, ECSA requests evidence of the four year instruction in a specific format. The problem is that lecturers each have their own e-learning layouts according to preference. This paper proposed and implemented a generic e-learning template that is aligned with the ECSA specifications for ease of archiving necessary evidence for the audit. It is however important to evaluate student feedback on this generic format so that the main purpose for e-learning as a learning tool is not missed by utilising it as a backup method. An exploratory study was employed to gather student perceptions on the new generic e-learning template. Four electrical engineering subjects' students were used as the sample group and Google Forms was used to collect the data in an online questionnaire. Of the 36 students who responded to the questionnaire, 94\% would recommend that all subjects adopt this generic e-learning template and $89 \%$ felt that having all their subject menus the same will make it easier to locate items. Due to the results of this study, the generic e-learning template will be adopted by all engineering subjects at the Central University of Technology, Free State with the addition of an introduction that explains the purpose and procedure of ECSA accreditation.
\end{abstract}

Keywords: e-learning; engineering education; engineering accreditation; ECSA; Engineering Council of South Africa. 


\section{Introduction}

"Quality is never an accident; it is always the result of high intention, sincere effort, intelligent direction and skilful execution; it represents the wise choice of many alternatives, the cumulative experience of many masters of craftsmanship. Quality also marks the search for an ideal after necessity has been satisfied and mere usefulness achieved" by William A. Foster (Forbes, 2017). At the Central University of Technology (CUT), National Diploma in Electrical, Electronic and Computer Engineering, quality is assessed by official accreditation bodies such as the Engineering Council of South Africa (ECSA). This is to provide quality engineering education programmes which adhere to the high standards set forth by the Washington, Sydney and Dublin Accords (ECSA, 2012).

Accreditation is appraised every four years, evaluating methods, evidence and outcomes. To ease this quadrennial accreditation visit the authors proposed, designed and implemented a generic e-learning template, aligned with the ECSA accreditations layout. The proposed layout could also ease site navigation for students. Preliminary implementation was done on four subjects namely; Control Systems III, Digital Systems I, Logic Design III and Digital Signal Processing IV. Student feedback was gathered in an online questionnaire using Google Forms. Feedback is used to evaluate the layout before the full deployment to all engineering subjects.

\section{Literature review of accreditation, e-learning and feedback}

Section 13 of the Engineering Profession of South Africa Act (No. 46 of 2000) indicates that ECSA must conduct accreditation visits to any education institution at least once during a four-year term. ECSA, in consultation with the Council on Higher Education (CHE), will then either conditionally or unconditionally grant, refuse or withdraw accreditation for any engineering programme offered at an institution of higher learning in South Africa.

Benefits of accreditation of any University of Technology programme means that it is recognized as satisfying the criteria prescribed for the relevant cadre of engineering practitioner. Additional benefits of accreditation confirm that the graduates from the respective programmes are ready for employment and are equipped to continue learning throughout their careers. It confirms that the qualification has a benchmark that can be used to establish its comparability with international qualifications, assure the public of the quality of the programme and encourage improvement and innovation in engineering education in response to national and global needs (ECSA, 2012). 
This four-year cycle accreditation is done by an accreditation team of two or more members from industry, one or two members who are active in the profession and one or two members who are academics. This team would request from the relevant lecturers (among other things) subject files for the last four years consisting of subsections as seen in Table 1 . Note that included in the safety and precautions heading is an additional HIV and AIDS brochure that was develop with student feedback as presented at the International HEAD'16 (Luwes, Meda, \& Swart, 2016).

Table 1. Screenshot of proposed template course menu.

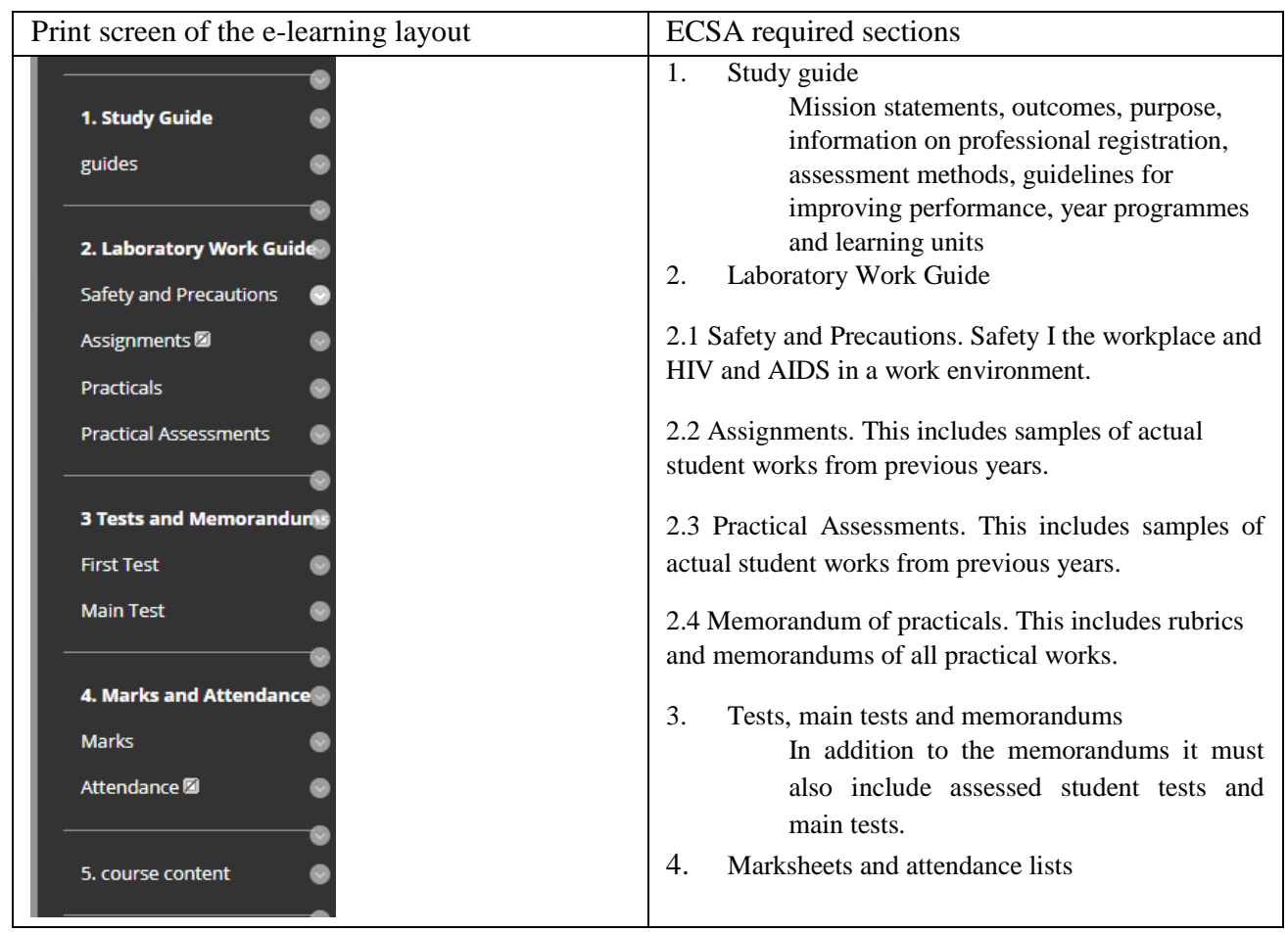

The table show the correlation between the ECSA required sections and the e-learning layout.

e-Learning might be a device that can assist in the four-year cycle accreditation as a backup tool. e-Learning is defined as instruction delivered on electronic devices that is intended to support learning, enabling students both on and off campus access to learning from any location where they have an Internet connection (Sleator, 2010). This means that e-learning is an umbrella term for all types of training, education and instruction that occurs in a digital medium, such as hand-held devices and computers using different types of media 
such as multimedia, social media or virtual classrooms. This trait makes it an effective tool in higher education as it allows the learning experience to transcend the traditional classroom.

Getting students to accept, and more importantly, continually use the e-learning component of their course, is essential for facilitators to blend technology with education (Hosam, Bee, Ahmed, \& Nasser, 2017). It is important to use student feedback in the design process and this may encourage them to keep using it.

Literature indicates that the adoption of student feedback was initially a contested topic, where it was mainly used as a performance management tool, but with on-going educational research, it has grown in recognition as a tool to enhance teaching and learning. Care must be taken in the design of suitable feedback questions that would generate relevant data for analysis. When analysing the data, one should focus attention on the use of the results rather than on the results themselves. A successful sustainable action plan should be implemented based on these results (Nair \& Mertova, 2011).

\section{Research Methodology}

An exploratory study was employed along with descriptive statistics involving quantitative analysis of the collected data. An exploratory design may set the stage for future research and usually involves only a single group of respondents (McNeill \& Chapman, 2005) (De Vos, Strydom, \& Delport, 2011). Descriptive statistics are used as the results are interpreted with regard to the proposed e-learning layout. Quantitative analysis is important as it brings a methodical approach to the decision making process, given that qualitative factors such as "gut feel" may make decisions biased and less than rational (Reddy, Higgins, \& Wakefield, 2014).

The target population was restricted to the students enrolled Control Systems III, Digital Systems I, Logic Design III and Digital Signal Processing IV of electrical engineering subjects. For ease of use Google Forms was used to obtain student demography and perspectives on specific questions relating to the new proposed layout. Closed-ended questions, featuring Likert scales, were used.

\section{Results and discussions}

The purpose of this paper is twofold. One, to propose a layout to assist in ECSA accreditation backup. Second, to present the students' feedback on the new proposed layout as well as perceptions on accreditation. 


\subsection{The proposed layout}

e-Learning has become an integral part of teaching. Thus, to utilize it for backup should be easy. The problem is that there are almost as many layouts as there are lecturers. A layout should be generic to ease navigation for students and assessors alike.

\subsection{Student perceptions}

The first few questions were designed to determine demography and perceptions on accreditation. A sample survey of thirty-six students answered the questionnaire. It consisted of $61 \%$ second year, $28 \%$ third year and $11 \%$ fourth year students. Their age representations are as follows: 18-21 years (33\%), 22-25 years (50\%), 26-29 years (11\%) and 30-34 years (6\%). Questions to determine what students knew about the accreditation process and accreditation bodies, showed that 33\% did not know what or who ECSA was and a more concerning 50\% did not know what ECSA accreditation meant for their institution. The same $50 \%$ did not know that lecturers needed to keep samples of practicals and assessments. Figure 1 shows the percentages of the students' perceptions on the menu layout.

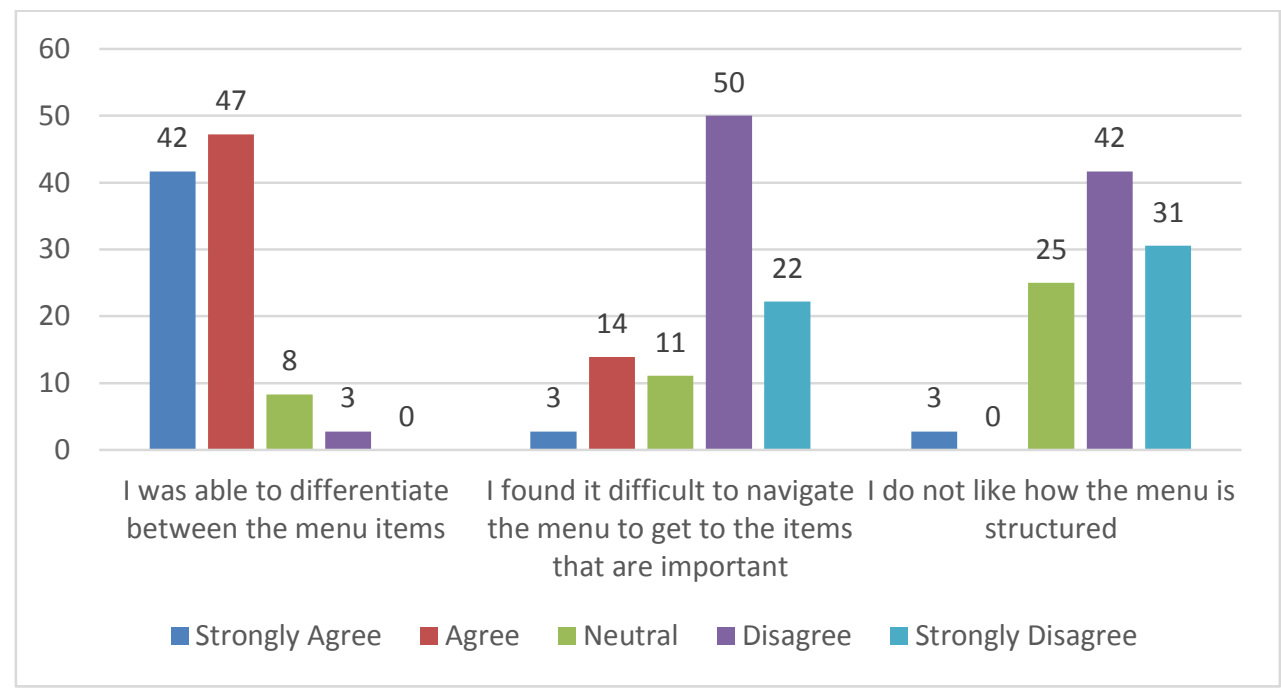

Figure 1. Student's perceptions on the menu layout

The questions as seen in Figure 1 "I was able to differentiate between the menu items", "I found it difficult to navigate the menus to get to items that are important" and "I do not like how the menu is structured" were setup to really evaluate the presentation of the menu layout. Eighty-nine percent (42\% strongly agree and $47 \%$ agree) indicates that students found it easy to differentiate between menu items and this correlates with the $72 \%$ (50\% 
disagree and $22 \%$ strongly disagree) that did not find it difficult to navigate the menu to get to the items that are important. Further validation is that $73 \%$ (42\% disagree and $31 \%$ strongly disagree) liked the menu structure. To assist in the backup process, it would mean that all practicals need to be handed in online. These perceptions were tested as follows. Figure 2 show the percentages of the perceptions on online submissions.

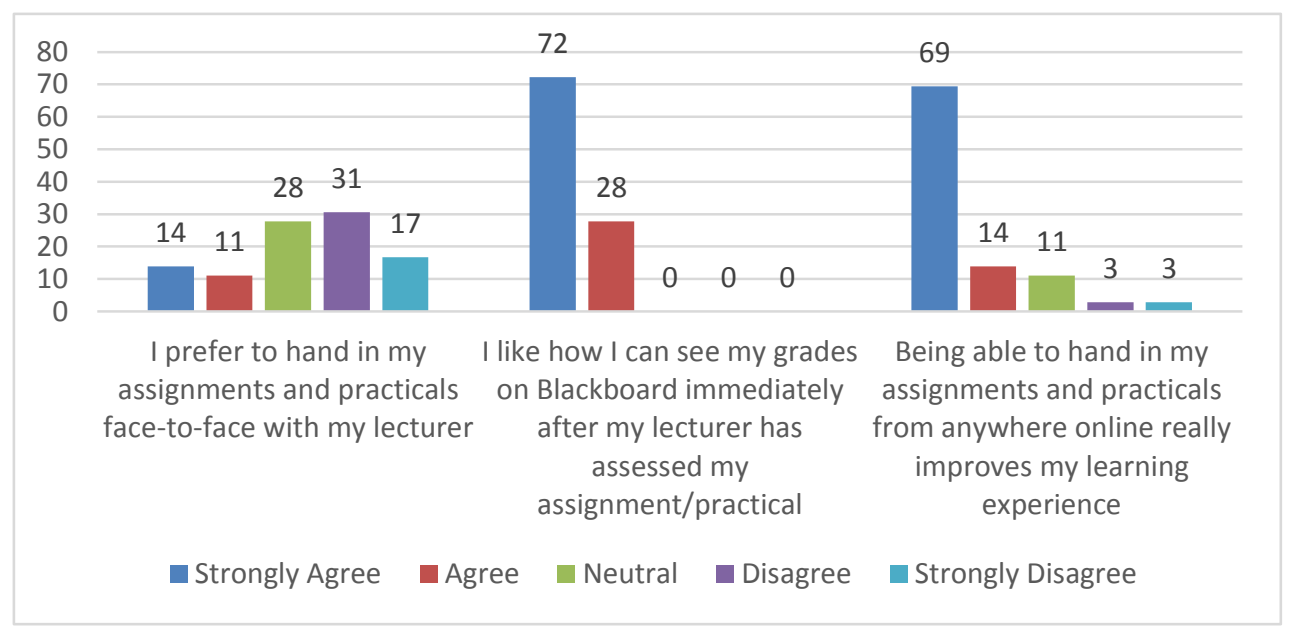

Figure 2. Perceptions on online submission.

These results are not overwhelmingly positive, but the distribution does indicate that it will be acceptable. This shows however a shift in the perception of submitting online as it contradicts previous perceptions that showed the majority of African undergraduate engineering students (more than 50\%) did not prefer to submit their practical work online (Luwes et al. 2015). Reasons seem to be that students appreciate the idea of being able to hand in assignments and practicals from anywhere online and that grades can be seen immediately after the lecturer has assessed it.

The new ECSA layout has different headings for assignments and practical assessment. The intent is that assignments are theory based and practical assessments are a multi-part assessment project that includes preparation, lab results and a report. A question was set up to see if students knew the difference. The overwhelming majority think that assignments are pieces of work that require an understanding of the theory, and that practicals are physical tasks or projects to be constructed and demonstrated. Some answers for this include: "Assignment could be practical but practicals are not necessarily assignments"," Assignments are pieces of work that require an understanding of the work done and research is necessary to understand. Practicals are when you see and understand the theory of a certain subject" and "This is a task that is allocated to a student or learner and it is to be handed in a specified time. Practicals are tasks that are physically done by a student with 
relevance to a module in a lab/class." These responses suggest that some students think assignments are preparation for practicals as seen in the following answers: "Assignment are usually research you do before doing the actual practical work" and "an assignment is something that you do research to find answers and practical you conduct an experiment to find answers". It also seems that students think assignments are the reports for practicals: "practicals are demonstrated immediately while assignments are submitted later". Figure 3 show the percentages of the overall perception.

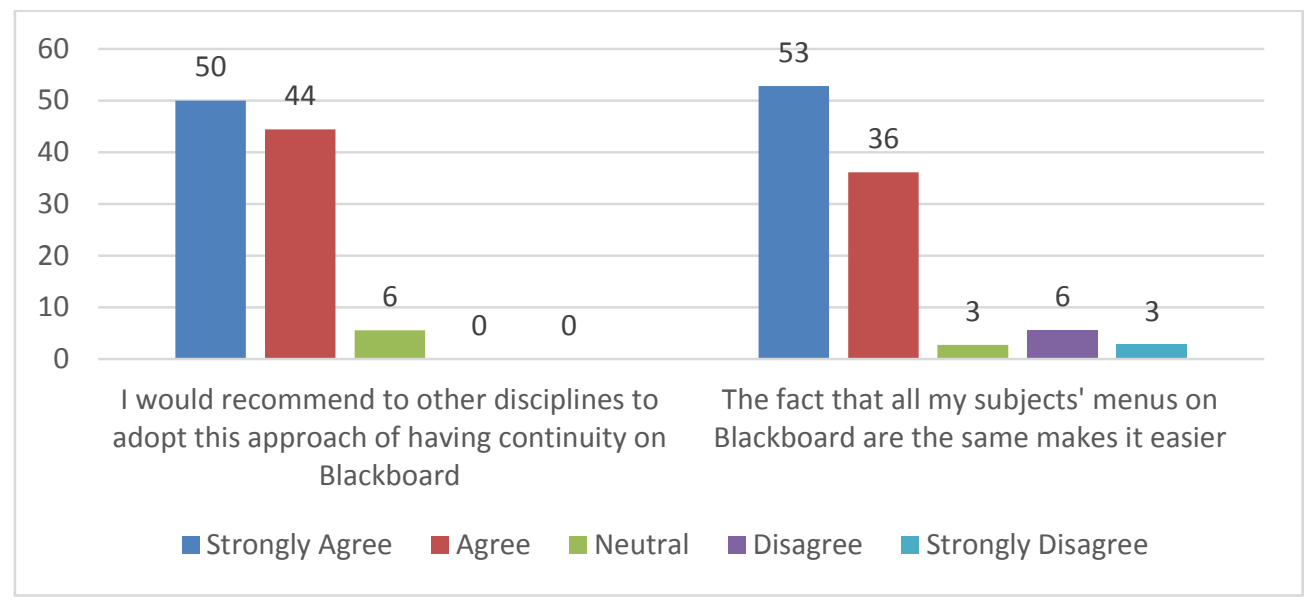

Figure 3. Overall perception

The overall perception of the generic layout is positive. Students indicated that they would recommend to other disciplines to adopt this approach of having continuity in the e-learning environment Only one student said no for the question "Would you prefer that all your lecturers adopt this template?" Students indicated that if all their subjects' e-learning menus would be the same that it would makes it easier (50\% strongly agreed and 44\% agreed).

The following responses were noteworthy: "The recent interface design changes make it look nicer than the last design", "It would be easier if eThuto notifications can be assessed instantly as WhatsApp, like whenever I have a notification it can pop up on my mobile device just as easily as possible" and "like an email, there should be an indication of announcements read and unread and also the dates."

\section{Conclusions}

This paper contribution is an e-learning layout to ease accreditation and student site navigation. It is however not known if ECSA would accept this form of backup, but as all evidences is in the required form it should suffice. Student perceptions was determined 
using feedback forms. Results showed a concerning fact that half of the respondents were not aware what ECSA accreditation meant to their institution, nor that their lecturers were required to keep evidence of their work. This indicates that student awareness of the reasons behind the design of their curriculum should improve. The majority of students found the new template design easy to navigate and positive perceptions of its use in other and future subjects. This shows that students enjoy the continuity of a generic template used in all their subjects. This generic template will be implemented as standard practice for all engineering subjects with the addition of an introduction that thoroughly explains to students how and why their curriculum is designed the way it is to align with the ECSA standards. Students will also be briefed on the mobile application of Blackboard that will allow them to receive notifications for any communication on their mobile devices. Positive feedback indicates that this generic template aimed to do backup should also improve the elearning experience.

\section{References}

De Vos, A., Strydom, H., \& Delport, C. S. (2011). Research at grass roots: For social sciences and human service professions. Pretoria: Van Schaik Publishers.

ECSA. (2012, November 22). Policy for accreditation of technology programmes in engineering. Retrieved from Engineering Council of South Africa: https://www.ecsa.co.za/about/pdfs/Accreditation_Universities_Technology_Section_1.p df

Forbes. (2017, November 22). Thoughts on the business of life. Retrieved from Forbes: https://www.forbes.com/quotes/9698/

Hosam, A. S., Bee, K. T., Ahmed, I. A., \& Nasser, A. (2017). e-Learning continuance satisfaction in higher education: a unified perspective from instructors and students. Studies in Higher Education, 1-18.

IEA. (2012, October 5). Homepage. Retrieved from International Engineering Alliance: http://www.ieagreements.org/

Luwes, N., \& Swart, A. J. (2016). Student perspectives of practical work done in a laboratory - a case study from Logic Design III. ICEE.

Luwes, N., Meda, L., \& Swart, A. J. (2016). Academic and student perceptions on the integration of HIV and AIDS education in an electrical engineering curriculum at a South African University of Technology. 2nd. International conference on higher education advances (HEAD'16) (pp. 160-168). València: Editorial Universitat Politècnica de València.

McNeill, P., \& Chapman, S. (2005). Research methods (3rd ed.). New York: Routledge.

Nair, C. S., \& Mertova, P. (Eds.). (2011). Student feedback: the cornerstone to an effective quality assurance system in higher education. Elsevier, 53-69. 
Reddy, W., Higgins, D., \& Wakefield, R. (2014). An investigation of property-related decision practice of Australian fund managers. Journal of Property Investment \& Finance, 282-305.

Sleator, R. D. (2010). The evolution of eLearning background, blends and blackboard. Science Progress, 319-334. 